\title{
EL PRINCIPIO DE SIMPATÍA COMO FUNDAMENTO PARA UNA ÉTICA DE UNIÓN ECONÓMICA Y SOCIAL*
}

\author{
Ángel Emilio Muñoz Cardona** \\ Recibido: septiembre 09 de 2010 \\ Aceptado: enero 20 de 2011
}

\section{RESUMEN}

La hipótesis que se intenta demostrar desde la concepción de la economía clásica es cómo la categoría de la simpatía se convierte en un principio cosmopolita de unión solidaria. Para demostrar esta hipótesis se utiliza la observación de los últimos eventos internacionales de unión simpatética y solidaria entre distintos ciudadanos del mundo ante ciertas condiciones económicas, sociales y políticas. Observación que será constatada con los escritos de los filósofos y economistas clásicos, Adam Smith y John Stuart Mill, quienes argumentaron que la justicia y la libertad sólo son posibles de ser pensadas en sociedades unidas por el sentimiento de simpatía, de allí que el fomento de la solidaridad y los sentimientos de empatía y de amor al hombre son el principio de valor moral fundamental en la construcción de los hilos sociales universales, son la condición primera para el logro del well being, la justicia distributiva, el progreso económico y el utilitarismo universal o felicidad general.

\section{PALABRAS CLAVE}

Simpatía, unión solidaría internacional, globalización, confianza y seguridad comercial

\section{CLASIFICACIÓN JEL}

B12, B23, B31

\section{CONTENIDO}

Introducción; 1. El principio de identidad solidaria; 2. La globalización no es una faceta del imperialismo; 3. Conclusiones: grada por grada; Bibliografía.

\footnotetext{
Este artículo es producto de la investigación doctoral en Filosofía Política y Moral que tuvo como fin abordar el origen de la ciencia de la economía en el pensamiento económico y filosófico de Adam Smith y John Stuart Mill. En este artículo se presenta el resultado parcial de la investigación que demostró a partir del axioma del hombre como ser social, la urgente necesidad de los gobiernos del mundo en educar a sus ciudadanos en valores morales de responsabilidad económica, política y social. Ejercicio del deber regulador de los gobiernos en la corrección de las fallas del mercado.

* Economista de la Universidad de Antioquia, Medellín, Colombia; especialista en Economía del Sector Público de la Universidad Autónoma, Medellín, Colombia; magíster en Filosofía de la Universidad de Antioquia, Medellín, Colombia; Ph. D en Filosofía de la Universidad Pontificia Bolivariana, Medellín, Colombia. Docente e investigador de planta de la Escuela Superior de Administración Pública, Medellín, Colombia. Colabora con el grupo de investigación sobre la deserción y la vida académica, Ingeniería y Sociedad de la Universidad de Antioquia, Medellín, Colombia. Correo Electrónico: angel.munoz@esap.edu.co, angelm@une.net.co.
} 


\section{THE SYMPATHY PRINCIPAL AS FUNDAMENT FOR THE ETHICS OF ECONOMIC AND SOCIAL UNION}

\section{ABSTRACT}

The hypothesis that tries to be proven from a classic economy conception is how the sympathy category becomes a cosmopolitan principal of solidarity union. In order to demonstrate this hypothesis, an observation of the last international events that involve sympathy and solidarity unions in between different citizens around the world under certain economic, social and political conditions is used. Observation that will be proven with the famous writings of the classic economy philosophers, Adam Smith and John Stuart Mill who stated that justice and liberty are possible only if thought in societies that share the common feeling of sympathy. .It is from this statement that the spread of solidarity and empathy is the main principal concerning moral value in the construction of social universal links, which are the primary conditions for achieving a wellbeing, a distributive justice, economic progress and general happiness.

\section{KEY WORDS}

Sympathy, international solidarity union, globalization, commercial reliability and safety.

\section{JEL CLASSIFICATION}

B12, B23, B31

\section{CONTENTS}

Introduction; 1 . Solidarity identity principal; 2. Globalization is not an imperialism facet; 3. Concluisons: grada por grada; Bibliography.

\section{O PRINCIPIO DA SIMPATIA COMO FUNDAMENTO PARA UMA ÉTICA DE UNIÃO ECONÔMICA E SOCIAL}

\section{RESUMO}

A hipótese que se intenta demostrar desde a concepção da economia clássica é como a categoria da simpatia converte-se num principio cosmopolita de união solidaria entre os distintos cidadãos do mundo ante certas condições econômicas, sociais y políticas. Observação que será contrastada com os escritos dos filósofos e economistas clássicos, Adam Smith e John Stuart Mill, pensadas em sociedades unidas pelo sentimento de simpatia, de ai que o fomento da solidariedade e os sentimentos de empatia e o amor ao home são o principio de valor moral fundamental na construção dos enlaces sociais universais, são a primeira condição para alcançar o well being, a justiça distributiva, o progresso econômico e o utilitarismo universal e a felicidade geral.

\section{PALAVRAS-CHAVES}

Simpatia, união solidaria internacional, globalização, confiança e segurança comercial.

\section{CLASSIFICAÇÃO JEL}

B12, B23, B31

\section{CONTEÚDO}

Introdução; 1. O principio de identidade solidaria; 2. A globalização não é uma faceta do imperialismo; 3 Conclusões: nível por nível; Bibliografia. 
Es necesario para una ética del futuro incluir no solo la formación de buenos ciudadanos sino, a demás, la de individuos excelentes que al tiempo que desarrollan sus capacidades personales se hermanan con los miembros de todas las naciones de la tierra

ESPERANZA GUISÁN (2008, p. 13)

\section{INTRODUCCIÓN}

Si bien los economistas y filósofos clásicos como Adam Smith $(1759,1776)$ y John Stuart Mill (1859, 1863, 1873 y 1874) reflexionaron sobre una ética global de la persona humana basada en la unión simpatética no alcanzaron a desarrollarla, pero sí la dejaron muy deducible a lo largo de sus obras. La simpatía como principio de transformación solidaria o de una ética pública internacional es hoy, gracias a los avances de la tecnología de la información, posible de ser pensada, como la pensaran los filósofos y economistas clásicos. De allí que para hablar de la aplicación del principio de simpatía en el contexto de la globalización actual, es necesario, que además de tomar en cuenta como los hechos de crisis social, ambiental, política y económica mundial, se tome en cuenta, como mecanismo para salir avante, la unión solidaria internacional'

Uno de los objetivos de política económica y social en los procesos de integración de las economías es el de lograr un capitalismo más humano a escala mundial, en otras palabras, de una economía con un Estado social de derecho cada vez más social y humano. La característica de comportamiento social, gracias a los avances de la tecnología de la información, de los ciudadanos y de los gobiernos de países más civilizados es la capacidad de cooperar y de ayudarse mutuamente; de allí la proliferación de organismos internacionales no gubernamentales, en

Cada vez es un lugar común ver cómo la prensa internacional y los organismos internacionales denuncian violaciones a los derechos humanos y de los animales en distintas partes del globo, lo que moviliza ayudas internacionales de ciudadanos del mundo, que velan por el bienestar universal, producto quizá, del desarrollo en la información, la tecnología y la electrónica que acerca a los pueblos o a los ciudadanos de todo el mundo y los hace más solidarios en su sentir simpatético. buen número, preocupados por la reducción de la pobreza y la condena a la violación a los derechos humanos ${ }^{2}$.

De esta manera, la solidaridad del mundo globalizado se afirma, según Mill (2002, p. 22), como "la única cierta y definitiva regla de conducta moral de mayor felicidad que escapa a las acciones del egoísmo individual", incluso de sobreponerse al egoísmo político de los gobiernos de turno por el bien de la dignidad humana universal, de motivar la reflexión en pos de la urgente necesidad de una estrecha solidaridad mundial en pro del bienestar, de la reducción de la pobreza y de la responsabilidad social sostenible. En últimas, de jalonar movimientos civiles internacionales atentos para denunciar públicamente cualquier violación al derecho humanitario internacional, o de condenar a cualquier gobierno de un país por permitir la existencia o dejar proliferar la pobreza en sus economías. Movimientos civiles de carácter mundial capaces de presionar ante organismos gubernamentales internacionales sanciones económicas y políticas a países violadores de la libertad, de la defensa del bien público internacional del medioambiente y de la dignidad humana, tales como Human Rigth, Solidaridad, Green Peace, UNESCO, OIM, OMT, Amnistía Internacional, Movimientos contra la pobreza e igualdad de género, entre otros. Movimientos civiles internacionales cuyo único objetivo es la defensa del hombre como ser sintiente, dignificar al ser humano como persona no como objeto o recurso para la explotación económica, en otras palabras, cui prodest?, es decir, ¿̇a quién apro-

\footnotetext{
El buscador Google registra más de 6.980 .000 archivos entre organismos internacionales de defensa y casos de denuncia internacional hechas por instituciones de protección a los derechos humanos en el mundo, el día 14 de septiembre de 2010 Ver página web: http://www.google.com.co/search?q=cu\%C3 \%Alntos+organismos+internacionales+de+ayuda+humani taria+existen+en+el+mundo\&hl=es\&tbs $=$ clir: 1, clirtl:en, clir t:en+many+international+aid+agencies+in+the+worldEsa $=$ XEei $=$ CO6PTIzLGYL98Aa33d3mDQEved $=0$ CEEO $\quad$ wEwCg. De igual manera, en Publicaciones Semana (2010) sacó una separata especial en la cual analiza la responsabilidad social empresarial en Colombia y cómo dichas prácticas solidarias toman fuerza social mejorando cada vez más la calidad de vida presente y futura en lo ambiental, social y económico.
} 
vecha?, la desunión entre los hombres y el egoísmo político gubernamental.

Para demostrar nuestra hipótesis de trabajo, se comienza por argumentar las diferencias sociales que implican hoy la globalización y la integración económica de los países, gracias a los principios de identidad simpatética y solidaria. No se trata de un simple intercambio de mercancías sino también cultural y de conocimientos, cambios que escapan al egoísmo del mundo comercial y nos crean nuevos paradigmas en las relaciones sociales. De allí que la globalización y la integración económica implican también un reto de unión cultural y de amor solidario entre los pueblos del mundo.

Es por lo anterior que podemos llegar a concluir que los sentimientos de orgullo y de amor propio nunca han tenido tanto sentido de cooperación universal como hoy. El altruismo universal, manifestado en los movimientos civiles, gracias a los avances de la electrónica, exalta en otros el ánimo social de vivir bien y mejor, de pensar que todo puede ser diferente si hay apoyo, de ver la justicia y la libertad como valores sociales supremos de dignidad del ser humano; y es que la electrónica facilita el entendimiento, despierta nuevas sensaciones y populariza los canales de comunicación, lo que favorece el disfrute del progreso universal y la calidad de vida buena.

Los avances en la tecnología de la información facilitan la educación universal de los sentimientos de simpatía entre los hombres, y mejoran de manera continua la unión civil solidaria en torno al amor de la persona humana. La popularización de la tecnología y sus bajos precios masificaron su uso y se lograron transformaciones sociales incalculables en la defensa de la dignidad del ser humano, hechos que la política de los gobernantes y la filosofía por sí solas no pudieron. En otras palabras, la tecnología de la información se convirtió en el espejo social del mundo civilizado 3 donde los países de economías

3 El concepto de civilización en las sociedades modernas está asociado a la capacidad que tiene un individuo, una comunidad o un país de deponer sus egoísmos o intereses más avanzadas muestran a otros el arte, el placer y la delicia del well being o del cómo vivir mejor.

\section{EL PRINCIPIO DE IDENTIDAD SOLIDARIA}

La globalización e integración de los países exige de sus ciudadanos identidad cultural y social, amor de patria, sentimientos de patriotismo. Es decir, países socialmente reconocidos por sí mismos y por los demás, en otras palabras, países con madurez política y social, países libres y autónomos porque reconocen el valor de ser Estado-Nación.

Lo anterior implica que cada país debe ganar primero sentido de pertinencia, reconocerse a sí mismo como nación antes de querer integrarse con los demás países; tener claridad sobre su origen y visión de futuro, en otros términos, tener autonomía, capacidad de autogobierno y amor propio. Para entender y valorar la originalidad de su cultura con importancia universal, los ciudadanos deben aprender de la ética a ser nacionales, a sentirse personas frente a otros, con capacidad de hacer lo que ellos hacen y mejor, a apreciar sus recursos, a amarse a sí mismos; a mirar al europeo, al asiático o al norteamericano como un igual. A no sentir complejos de inferioridad; para ello la educación deberá estar basada en el valor de la identidad cultural, pero también, en el respeto y en el reconocimiento de las diferencias. En la universalidad de las culturas y en su importancia en la formación de una conciencia social. Al respecto González (1995, p. 14).

¿No es de vulgar observación que en Suramérica se lee mucho, que saben un poco de todo, que son vivarachos, etc.? ¿No está la explicación en lo que acabo de anotar? ¿No observan todos que a pesar de leer tanto y saber tanto, el suramericano nada crea? Pues muy fácil

particulares por el bienestar general o universal, es decir, de un mayor número de personas. Concepto ampliamente trabajado por el filósofo moral John Stuart Mill, como lo veremos más adelante. El concepto de globalización deberá entenderse en la definición que nos da la Real Academia de la Lengua Española en el 2010 "Tendencia de los mercados y de las empresas a extenderse, alcanzando una dimensión mundial que sobrepasa las fronteras nacionales". 
explicarlo: tienen vergüenza, simulan, leen, etc., porque están obligados por el coloniaje político, racial y literario, a considerarse como hijos de puta. Me enorgullezco de ser el primero que ha estudiado y analizado el complejo que he llamado hijo de puta. Aquí han dicho que uso palabras inmundas; lo que sucede es que estudio problemas nuevos, suramericanos ${ }^{4}$.

Cada nación deberá primero pensarse a sí misma como República independiente, entenderse en su individualidad y en su unidad nacional, antes de pensarse como continente o como grupo económico y social unificado. Para ello deberá prestar una especial atención en la formación de la identidad cultural y de las distintas culturas que se han unido para formar una sola, así como la del colombiano se ha unido para formar una misma nacionalidad, respetándose cada una en sus diferencias: la del antioqueño con la del indígena o del afrodescendiente con el romo o gitano. Formar en el valor cultural de sus raíces, de tal manera que sea posible el orgullo de la pertinencia, y por tanto, la búsqueda conjunta del bienestar. El filósofo antioqueño Luis Fernando Fernández (2008, p. 9) afirma al hablar del bicentenario y de la identidad hispanoamericana, lo siguiente:

América hispánica es el Continente de la esperanza, de las expectativas y de la imaginación; es el Continente proyectivo, vectorial, orientado hacia el futuro; el Continente de la resistencia, la solidaridad, la espontaneidad vital y la convivencia y, por encima de todas las dificultades, las desigualdades y la inseguridad, y a pesar del dolor y la injusticia, es el Continente en el que es posible la alegría.

La unión solidaria entre los países con un mismo sentir debe nacer primero del principio de simpatía en la identidad, en la aceptación de un origen común que los une y aglutina, que los convoca al

4 El filósofo envigadeño Fernando González (1973, p. 11) define el término hijo de puta "En los Negroides" como aquél que se avergüenza de lo suyo. "Por aquí me han llamado grosero porque uso esta palabra, pero la causa está en que mis compatriotas son como el rey negro que se enojó porque no lo habían pintado blanco". diálogo, a reunirse para actuar como una familia de naciones con un origen y una cultura común, países que desde su independencia son capaces de establecer una soberanía compartida. Sería como afirman el español, Marías (1990) y el antioqueño Fernández (2008, p. 12), consolidar una comunidad con un proyecto común, poniendo en primer plano los intereses comunes de ambas comunidades de hispanoparlantes -la española y la hispanoamericana- una realidad que va más allá de la lengua ya que comprende una misma historia durante más de tres siglos, formas sociales, costumbres, lecturas, creencias, estilos de vida, los valores cristianos (profésese o no la fe) y mucho más ${ }^{5}$.

\section{LA GLOBALIZACIÓN NO ES UNA FACETA DEL IMPERIALISMO}

Algunas personas creen ver en la globalización de la era del conocimiento otra faceta del imperialismo, una dominación que se ejerce al individuo a través del consumismo; una conquista del capitalismo de los países desarrollados que hace más dependientes a los ciudadanos de los países pobres al volverlos más consumidores y obligarlos al endeudamiento; una manera de acabar con la industria nacional al ser incapaz de competir y, por tanto, de entregarle el mercado doméstico a las multinacionales, en otras palabras, es la mejor manera de acabar con las empresas nacionales y el apego cultural por lo autóctono. Al respecto Sen y Kliksberg (2007, p. 17-18) plantean:

Por supuesto, hay aspectos vinculados a la globalización que se conectan con el imperialismo (la historia de conquistas, colonialismo y dominación extranjera siguen siendo pertinentes en muchas formas) y una forma poscolonial

\footnotetext{
5 Es necesario que antes de pensarse en una unión económica y social entre los distintos países, debería pensar primero en la consolidación de unión nacional interna que de fin a los conflictos internos de reconocimiento entre sus nacionales y no se dé pie a la exportación, a través de la unión de los países, de prácticas de violencia. España debe lograr identidad y unidad nacional, así como Estados Unidos, Ecuador, Colombia, Irlanda, etcétera.
} 
de comprender el mundo tiene su mérito. Pero sería un grave error ver la globalización fundamentalmente como un rasgo del imperialismo.

Es mucho más y reviste mayor grandeza.

El problema económico no es simplemente un tema de ganancias comerciales, es también un tema de distribución de beneficios, de negociación y, por sobre todo, de transferencia de conocimientos, de trabajo conjunto por la defensa de los derechos humanos y ambientales. Es papel de los gobiernos estimular las inversiones a través de políticas fiscales; propiciar el diálogo entre oferentes; facilitar los procesos de negociación; mejorar los acuerdos con respuestas concretas a preguntas sociales tales como: ¿̇se mejora la calidad de vida de la población con la competencia?, ¿qué tanto se benefician las clases más pobres a presente y a futuro con estos acuerdos?, ¿qué convenios de intercambio de conocimientos entre empresas y gobiernos nacionales e internacionales se deben acordar de tal manera, que se fortalezcan centros de educación nacional?, ¿cómo financiar un mayor beneficio social?, ¿qué papel juegan la sociedad y los movimientos sociales no gubernamentales?

Las sociedades civilizadas, es decir, que han sido formadas en una conciencia civil y de amor al hombre como persona humana demandan de los gobiernos nacionales respeto y protección a la dignidad del ser humano, obligando a los gobiernos a promulgar leyes de control a la concentración de capital, abusos de los precios, a la búsqueda de ganancia a costa de la desmedida explotación del trabajo humano; la sociedad civil debe exigir a los gobiernos regulación para que los mercados no celebren acuerdos que beneficien sólo a los intereses del egoísmo privado; es deber del gobierno estar presente y obligar a la celebración de acuerdos comerciales que beneficien realmente a la sociedad civil, es decir, que reduzcan la pobreza y las desigualdades; corregir desequilibrios del mercado, velando por los intereses de las clases más pobres, de tal manera, que todos salgan ganando.
No se trata de prohibir sino de alterar acuerdos de negociación con fines más públicos, de utilidad o de felicidad general ${ }^{6}$. El fin de los intereses políticos es el de ayudar a la generación de nuevas ideas empresariales, de acercar a todos sus ciudadanos al deber social de la globalización, de abrir nuevas oportunidades. En otras palabras, de ser visionarios, de transformar la ética pública y la conciencia ciudadana universal ${ }^{7}$.

Desde esta perspectiva la globalización es mucho más que el consumo por el consumo o el embolate de la libertad del consumidor. La globalización es también transferencia de conocimientos, de información sobre las condiciones de vida de todos los seres en el mundo, es una relación entre gobiernos que presionados por una creciente simpatética y solidaria sociedad civil internacional obligan a la existencia de acuerdos políticos de interés común en pro de la dignidad de las personas humanas: reducción de la pobreza, mejoras en las condiciones de vida y del desarrollo sostenible ${ }^{8}$.

6 Por ejemplo, descontando o reduciendo impuestos a las empresas que financien, patrocinen obras de interés público como escuelas, laboratorios, mantenimiento de parques, etcétera. Otra forma es facilitando la competencia empresarial, la cual en su afán de competir promete mayores beneficios a sus consumidores, bien a través de la financiación de fundaciones o de calidad en los productos, entre otras.

7 Lo anterior significa un cambio en la política internacional liderada por la ONU y la OEA donde prime el bien público universal sobre el bien particular de las naciones. Para los filósofos y economistas clásicos la utilidad individual está supeditada a la utilidad de la comunidad y esta a la utilidad social y, esta última a la utilidad universal. No es justo que el interés económico de las industrias de armamentos de las economías más ricas del mundo prime sobre el bienestar y la paz de las naciones más pobres. O simplemente que el beneficio económico de un país prime sobre la sociedad civil de naciones que viven bajo dictaduras y regímenes de violencia en América Latina. No es necesario el uso de la fuerza para deslegitimar una acción bárbara o no buena, basta con la desaprobación, con la antipatía, con el ejercicio del olvido, con el no reconocimiento, en otras palabras con el no apoyo comercial tanto de bienes y servicios como de armas.

8 Entre enero 25 y febrero 18 de 2011, ciudadanos egipcios se unieron en un gran movimiento civil, sin precedentes en el mundo árabe, para destituir al presidente Hosni Mubarak después de haber gobernado por 30 años a Egipto. El éxito del movimiento civil, llamado movimiento blanco por no haber sido sangriento, contó con el apoyo internacional, gracias al sentimiento de simpatía que se despertó en la solidaridad internacional al poder ver, leer y escuchar por Internet, 
En otras palabras, llegar a acuerdos justos que beneficien a todos los hombres, porque ningún ciudadano es más que otro o de mejor raza que el otro. Casi todos los hombres poseen el mismo sentir, el mismo anhelo de superación; de allí la necesidad internacional de ayudas mutuas en la que los países se interesan por el bienestar de los hombres. No basta con saber que los ciudadanos de un país están mejor que los de otros países, es necesario que cada vez más ciudadanos del mundo estén bien, con lo que se evitarían fenómenos migratorios o de desplazamiento forzoso, políticas xenofóbicas contra inmigrantes, violaciones disfrazadas a los derechos humanos por agentes de control de fronteras en países que intentan proteger sus economías. Todo ser humano desea ser tratado como persona, respetado en su integridad moral y física, tener futuro, progresar económicamente, llevar una vida feliz, placentera y en paz.

Si un país ofrece a sus ciudadanos un gobierno honesto, transparente, abre oportunidades de empleo y facilita posibilidades de mejoramiento se convierte en el lugar ideal para vivir, tener familia y soñar. Pero si un país descaradamente y sin control ofrece la existencia de un gobierno corrupto, oportunista, brinda pocas oportunidades de empleo y de autorrealización, los individuos se sienten engañados, desilusionados, por lo que tendrán en poca estima sus instituciones y podrán sentir, incluso, vergüenza de afirmar su nacionalidad.

Los individuos aman sus lugares de nacimiento o de cultura no porque sean estéticamente bellos sino

teléfonos móviles, redes sociales el drama que allí se vivía, lo que llevó a la conformación de movimientos solidarios, marchas callejeras de ciudadanos europeos y americanos pidiendo a sus gobiernos que intervengan en favor de los ciudadanos egipcios, deponiendo sus intereses políticos personales. Gracias al apoyo de esos grandes movimientos civiles internacionales el presidente derrocado no pudo usar abiertamente la fuerza pública o la violencia para acallar el gigantesco movimiento civil en su país. Por el contrario, se vio forzado a mantener los sistemas de comunicación y de información abiertos al público internacional. De esta manera, los ciudadanos del mundo, en su inmensa mayoría jóvenes, se ponen por encima de los intereses políticos de sus gobiernos y los obligan a actuar conforme a una ética universal para el bienestar general. por el bienestar social que ellos generan y que para ellos representan; los habitantes aman sus calles y lugares porque les dan felicidad. La selva puede ser hermosa para quien vive dentro de ella por placer y por voluntad propia, le es incluso saludable. Muy diferente siente el que vive en ella por obligación y no tiene esperanza de progreso; nada le parece hermoso, odia cada rincón de ese lugar por cuanto le representa fracaso, desilusión, frustración, aburrimiento, sufrimiento y, quizá, vergüenza por los sentimientos de inferioridad. Como lo muestra Fernández (2008, p.2):

En los últimos tiempos las cosas han ido mejorando considerablemente, tanto porque cada vez hay mayor madurez cívico-política como por la claridad de algunos de los actuales dirigentes nacionales en cuanto a no negociar los principios éticos y constitucionales.

Los ciudadanos aman a sus países no porque ellos sean ricos o pobres sino por el grado de pertinencia alcanzado. Si bien los países cuentan con diferentes grados de desarrollo y de recursos, el verdadero amor de un ciudadano nace del esfuerzo conjunto, de la manera como los gobernantes enseñan a sus gobernados, bajo el imperio de la justicia, a salir adelante. Entre más justo y honesto sea el gobierno de un país, más ama el nativo su tierra y su identidad cultural; más orgullo se siente de su origen, no es la riqueza mal distribuida, ni la opulencia de unos y la miseria de otros lo que hincha de orgullo a un nacional sino la justicia emanada del buen gobierno.

\section{CONCLUSIONES: GRADA POR GRADA}

Si aceptamos con Mill (1986) que el utilitarismo es la búsqueda de la felicidad general, entonces, ha de ser un imperativo el aceptar que antes de un país celebrar acuerdos de integración comercial y social deberá primero darse en su interior, una unidad ciudadana, de reconocimiento, de identidad entre cada uno de sus nacionales, de amor propio a su cultura y a la persona humana. De respeto a la 
libertad soberana de cada hombre a ser persona. Deberán primero aprender a ser Nación civilizada, ordenada, segura de sí misma en su interior; tener como cultura de comportamiento los valores morales de respeto, prudencia y tolerancia frente a la diferencia, lo que garantiza el logro de la felicidad general al querer buscar ser ciudadanos del mundo.

Los gobiernos del mundo, antes de pensar en una integración hacia fuera, con distintos países, deberán primero fomentar entre sus nacionales el amor al hombre, al otro como persona humana, y a lo otro como diferencia que enriquece. Con ello, se evita el nacimiento de posiciones ideológicas de fanatismo racial, territorial o religioso que lleven a movimientos xenofóbicos en los que se pierde el valor del otro como persona humana. Se deberá fomentar la templanza moral, tanto en lo ideológico como en lo político, en lo cultural, en lo deportivo, de tal manera que se deje espacio a la existencia de la diferencia del otro y de lo otro, donde no se dé lugar al fanatismo extremo, de tal manera que reine la debida prudencia. Condición de formación universal que favorece los sentimientos de simpatía entre todos los ciudadanos, es decir, el florecimiento de las empatías, del reconocimiento de las diferencias culturales y de las experiencias distintas de vida. Sentimientos de simpatía que al fortalecerse en la entropía facilitan los movimientos solidarios universales capaces de conformar una unión económica y social; de defender la soberanía de todo hombre a la libertad y al derecho de ser tratado como persona sintiente. Principios universales de toda economía para el libre mercado.

Si aceptamos con Smith (1997) que es deber de los gobiernos del mundo impulsar la educación social y política entre sus ciudadanos más pobres, de tal manera que se evite el decaimiento moral de la sociedad y se evite llegar a la pérdida de dignidad humana en interior de sus ciudades, entonces, es necesario aprender a amarnos a nosotros mismos, de esa manera se evita que sociedades insolidarias llenas de recursos terminen siendo violentas y subdesarrolladas. Por el contrario, una sociedad de hombres solidarios con responsabilidad social y civil será una sociedad política viable porque es capaz de velar por el bien ciudadano, de controlar los desmanes del mercado, de no dejar que ahonden los egoísmos comerciales, que a veces inocentemente propician los gobiernos de las naciones bien por presiones empresariales o por la dinámica del mismo afán de la maximización de utilidades o del beneficio propio, sin importar el bien de la utilidad general.

Finalmente, para demostrar nuestra hipótesis de trabajo, el logro del bien general, es decir, el cumplimiento universal de bienestar general penden de la conciencia simpatética universal que facilita la existencia de los movimientos sociales solidarios no gubernamentales en procura de la defensa de la dignidad humana, del reconocimiento del otro como persona y no de la libertad de mercado o de los principios de maximización de las utilidades económicas o de la búsqueda de las economías de escala. La economía o la integración económica sola no garantizan el bien general de la felicidad porque no son capaces de reconocer al hombre como persona humana sino como recurso idóneo de producción.

\section{BIBLIOGRAFÍA}

Fernández Ochoa, Luis Fernando. (2008). España, Plaza Mayor de Hispanoamérica. Medellín. Ponencia del Primer Congreso Latinoamericano: identidad y cultura. Universidad Pontificia Bolivariana. Septiembre 23-26.

González, Fernando (1995). Los negroides. Medellín, Universidad Pontificia Bolivariana, quinta edición. Prólogo de Ernesto Ochoa Moreno, 60p.

González, Fernando (1973). Los negroides. Medellín, Editorial Bedout S. A., tercera edición, 55p.

Guisán, Esperanza. (2008). Una ética de la libertad y solidaridad: John Stuart Mill. España: Anthropos, 127p.

Marías, Julián (1990). El mosaico. Diario El Colombiano, Dominical, domingo 23 de Septiembre, Medellín, p. 10. 
Mill, John Stuart. (1986). Autobiografía. Madrid: Alianza Editorial, Prólogo de Carlos Mellizo, 295p.

Mill, John Stuart. (1995). La utilidad de la religión. Madrid: Alianza Editorial. Edición en español, Prólogo de Carlos Mellizo, Universidad de Wyoming, 100p.

Mill, Jhon Stuart. (1997). Sobre la libertad, Madrid: Alianza Editorial, Prólogo de Isaiah Berlin, 210p.

Mill John Stuart (2002). El utilitarismo. Madrid, España: Alianza Editorial, Filosofía, Traducción de Esperanza Guizan, 158p.

Publicaciones Semana (2010). Empresas sostenibles: todo lo que usted debe saber del desarrollo sostenible en el país. Publicaciones Semana del Tiempo, separata especial, Bogotá, junio 7, 114p.
Sen Amartya y Kliksberg Bernardo (2007). Primero la gente: una mirada desde la ética del desarrollo a los principales problemas del mundo globalizado. Barcelona: Ediciones Deusto, 117p.

Smith, Adam. (1997). An Inquiry into the Nature and Causes of the Wealth of Nations. Obra publicada en español en 1992 con base a la edición de 1776 por el Fondo de Cultura Económica, México, D.F.:17. Traducción en español. Investigación sobre la naturaleza y causas de la riqueza de las naciones. México: Fondo de Cultura Económica, novena reimpresión, 918p.

Smith, Adam. (1997). Teoría de los sentimientos morales. Madrid: Alianza Editorial, Prólogo de Carlos Rodríguez Braun, 612p. 